\title{
Performance Evaluation of Locally Designed and Produced Parabolic Solar Cooker
}

\author{
Samuel Jacob Aliyu ${ }^{1, ~ *}$, Chiebuka Timothy Nnodim ${ }^{1}$, Kazeem Rasaq Adebayo ${ }^{1}$, \\ Adedayo Aaron Banji ${ }^{2}$ \\ ${ }^{1}$ Department of Mechanical Engineering, Landmark University, Omu-Aran, Nigeria \\ ${ }^{2}$ Department of Electrical and Information Engineering, Landmark University, Omu-Aran, Nigeria
}

Email address:

aliyu.samuel@Imu.edu.ng (S. J. Aliyu)

${ }^{*}$ Corresponding author

\section{To cite this article:}

Samuel Jacob Aliyu, Chiebuka Timothy Nnodim, Kazeem Rasaq Adebayo, Adedayo Aaron Banji. Performance Evaluation of Locally Designed and Produced Parabolic Solar Cooker. International Journal of Energy and Environmental Science.

Vol. 6, No. 4, 2021, pp. 96-106. doi: 10.11648/j.ijees.20210604.14

Received: January 12, 2021; Accepted: January 19, 2021; Published: August 27, 2021

\begin{abstract}
Despite being able to supply beyond energy required for global use, the sun is still being greatly under-utilized possibly due to the availability of alternative sources of energies which are finite, costly, and far more hazardous. The aim of this research work is to seek better ways of utilizing the luminous flux (luminous energy emitted per second) or power from solar radiation, which is renewable, pollution free and which is freely available to mankind to generate heat or power required for cooking and for related needs of a cooker. The solar cooker, which is a family size type was designed (with the design specification temperature of $180^{\circ} \mathrm{C}$ ) which was constructed and tested between the periods of 9.00 am and 4.00 pm during sun shine days. The maximum temperature attained was $140^{\circ} \mathrm{C}$. The parabolic solar cooker has four panel booster reflectors (with rectangular plane mirrors on each booster reflector) each of which is detachable and a mechanical device is provided to constantly tilt the reflectors in the azimuthally direction so as to track the sun. These reflectors reflect the sun rays which falls incident on it to a focal point which give solar energy of high intensity. A known size pot was positioned with aid of a potholder on the focal point. The use of the parabolic cooker will help tremendously in the conservation of fossil fuel energy. However, on the sunny and cloudless days, the cooker can work effectively for various cooking purposes at almost the same rate as the conventional stoves. The efficiency of the cooker was determined and recorded. Finally, the cooker could be more efficient if the entire reflector surfaces of the cooker can be able to radiate heat energy from all its surfaces to the focal point. The cooker could be used for cooking on sunny days and in areas where electricity availability is questionable in terms of supply.
\end{abstract}

Keywords: Reflector, Parabolic Solar Cooker, Temperature, Energy, Luminous, Efficiency

\section{Introduction}

Energy, the ability to accomplish physical work, comes to our attention principally for an economic advantage and as an input to our intermediate goods processing. The energy demanded is not just hunted for its own sake. The natural use of energy from its source is considered as an asset for the production or utilization of final product. The ultimate realization of energy has brought about the economic development of our daily basic needs with increased energy used per capital. Solar energy been the source of existence maintenance this energy is stored in living things (plants and animals) and this source can be identified continuously through these living things, wind energy and fossil fuels. Most forms of heat inputs produce some measure of pollution (which is not environmentally acceptable), since waste products occur along with the desired goods. Due to high demand for energy, people are beginning to see the energy crises in a very different light. The problem imposed by growth in energy consumption applies almost equally to renewable sources of energy [1-3]. Even though they cannot be depleted, costs will rise rapidly and supply will decline [4]. There are two main categories of energy sources and they are: 
the exhaustible sources (fossil fuels-gas, crude oil, and natural gas) and the in-exhaustible sources such as continuous sources-hydro, wind, tidal, and solar energy. The exhaustible sources are also known as the non-renewable energy source while the in-exhaustible sources are what is referred to as the renewable energy source. According to Joyee and Rahman [5], integration of renewable energy sources into energy supply systems will minimize problems associated with finite fossil fuel resources and environmental deterioration due to emissions from fossil fuel-based energy system. Ultimately renewable energy system will replace fossil-fuel based energy sector [6-8]. Direct solar radiation can be harnessed for variety of purposes, including heating and cooling of building, water heating, agricultural drying and so on. Solar energy is an alternative natural energy sources for mankind in meeting his energy need for the future [5]. Solar energy has a non-polluting phenomenal, it possesses a great amount of energy which can be converted into several orders of magnitude greater than the present world energy demand. The quantity of energy received by the earth from the sun is tremendous, but it is also quite diffused. The intensity of solar energy outside the earth atmosphere is above $0.333 \mathrm{Kcal} / \mathrm{m}^{2} \mathrm{~s}$, and out of this, about $30 \%$ is lost in atmospheric layers. The total energy falling on the earth turns out to be about $708 \times 10^{14} \mathrm{kCal} / \mathrm{s}$ i.e. some 30,000 times the energy consumed at present [9]. Solar energy represents an almost inexhaustible source of energy. In Nigerian and in most African countries, fossil fuel has been the major means of obtaining energy. Renewable sources like wind, geothermal, photovoltaic cell, and other forms have not been properly harnessed.

However, the era of cheap fuel (coal, wood, petroleum and so on.) is diminishing, invariably pointing to the need of exploiting and harnessing renewable energy source as paramount. In Nigeria, the potentials for solar cooker being used for solar cooking will be of tremendous impact especially in the tropics where the sun's rays are almost directly incident on the earth surface [10]. Therefore, more research should be done on the use of solar energy so as to reduce the over dependence on the sources of energy which forms the basis of this research work which was aimed at improving and modifying the existing types of solar cooker for obtaining higher efficiency and better aesthetics of the parabolic cooker to suit the choice of users and as well for other uses. Because the earth is such a small target in the solar system, only about one-fifty-millionth of the abundance of its heat energy output arrives the earth's outer atmosphere (190 km above earth's surface), and it does so at a constant rate [11]. This constant rate is known as the solar constant. The effective surface temperature of the sun is about $5762^{\circ} \mathrm{K}$. The temperature of the sun's interior is estimated to be at $8 \mathrm{x}$ $10^{6}$ to $40 \times 10^{6} \mathrm{~K}$, and the density is about $80-100$ times that of water [12]. The star (sun) has three layers, the photosphere, the atmosphere and chromosphere. The photosphere is the source of solar radiation while the atmosphere has lesser transparency than the photosphere. For many purposes (such as thermal process) the sun is adequately considered as a black body radiator at about $5762 \mathrm{~K}$ [13]. From general observation, it is observed that the intensity of the sun's radiation at a given time and place and the angle at which its rays strike a surface are dependent upon the season of the year, the degree of cloudiness and the tilt of the surface with respect to the horizontal. The sun energy estimated to be falling on the horizontal surface in Nigeria is $23000 \mathrm{~kJ} / \mathrm{m}^{2}$ [13]. Finally, the greater the hours of sunshine per day, the greater the intensity of the sun; this means that there are more hours of sunshine in Minna as from January to April every year than other months [14-16].

The objective of this research was to provide the cheapest techniques for cooking with solar energy in developing countries. In Nigeria, majority of our women in rural areas, towns and villages cook meals daily using firewood or charcoal. The increasing consumption of biomass fuel show the decline in the availability of the resource especially in the Sahelian zone of African. In this part of the world, every household have to travel a great distance to obtain biomass resource. The children become venerable to high risk of accessing this commodity by paying higher prices in favour of their education. The deplorable conditions of these children leads to unacceptable poverty, serious educational backwardness, disturbing health challenges, environmental degradation leading to deforestation and desertification [1719]. A better alternative to curb this negative effects at house hold level, is the implementation of the use of the solar energy for household utilization, thereby making life meaningful for an average mankind and reducing the total dependence on biomass fuel or fossil fuels. This will also help to obtain higher but safe temperature for fast cooking through the continuous improvement and modification of solar cookers. By this, there will be better means for faster, cleaner, and less costly cooking.

\section{Materials and Methods}

\subsection{Material Selection}

Materials for the entire assembly of the parabolic dish multi-solar cooker (PDMSC) were considered during the design before the construction were finally implemented. (Table 1). The parabolic dish curvature should be able to reflect solar radiation heat from the reflecting mirror to the cooking pot; thus, consuming less time and enabling a better long life for the cooker. The materials selected for the construction is mild steel which is more preferable than aluminum considering its strength, durability, and rigidity. Production of steel is estimated to be $16500 \mathrm{~kJ} / \mathrm{kg}$ compared to that of aluminum of $141,000 \mathrm{~kJ} / \mathrm{kg}$ [4]. During the construction process the pot holder and the reflector were assembled and mounted on a frame structure. The parabolic dish assembly frame is again supported by basement structure which is also made out of a flat bars and MS angles. Parabolic dish could be swigged along $180^{\circ} \mathrm{C}$ in the direction of the Sun for tracking purpose. The parabolic dish reflecting plane mirrors were cut to geometric sizes and then glued to 
the curvature shape of the dish by a plastic mold. Aluminum pot and the stainless pot were used for cooking because they have good thermal conductivity, better corrosion resistance, and good absorbing capability of heat and with a good weight quality. These utensils are obtainable in the local market and most especially they offers the user an advantage of ease of changing their external illumination with a different colour quoting of their choice, in this case using black colour [5]. Solar reflecting systems for research activities, e.g. plane mirrors, need high quality and good specular reflectance properties [19-25]. Plane mirror of $2 \mathrm{~mm}$ thickness was used putting into consideration the cross weight of the parabolic dish. A plane mirror with high polished surface could attain reflectivity of $95 \%$ which is acceptable than that of aluminum (85\%). Black colour have higher absorptivity of sun energy at angles of sun reflection other than normal incidence; they also adhered to the material surface and are durable during operation, therefore black paint is used for the absorber coating, Figure 1.

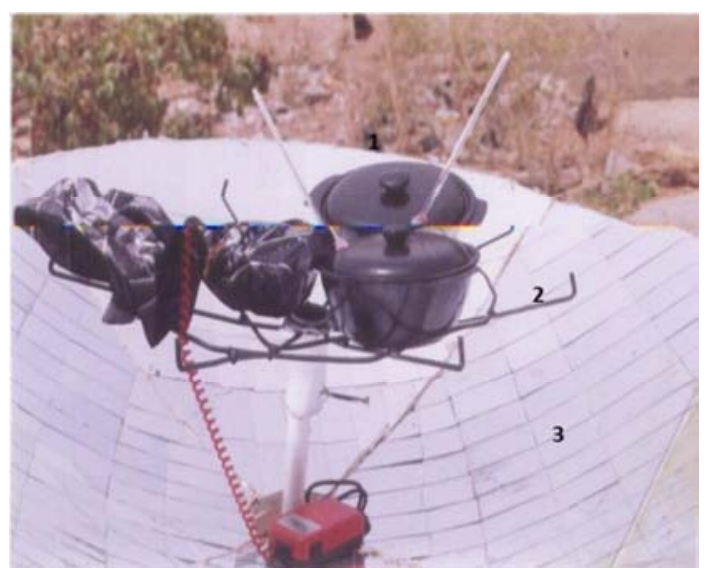

Figure 1. Experimental set-up of parabolic dish multi-solar cooker, 1-pot; 2pot holder; 3-reflector.

The experiment was done in Niger State, Nigeria. The African continent, Figure 2a, identify the regional intensity of direct normal irradiance (DNI), and also Figure 2b identify the regional location map of Niger State. Our mother continent in totality experiences 365 days of direct sunshine in a year, while the northern and southern regions experience the best DNI locations on earth. Having this awareness makes it possible to maximize the use of the solar intensity in Africa which is a profitable and sustainable venture [6]. Some major geographical zones on earth have more of sunshine reaching the earth's surface. Naturally having these zones lying between $15^{\circ}$ and $35^{\circ}$ latitude north and south seem to be most favorably placed. This geographical zones experiences little rains fall and clouds which means that more than $90 \%$ of incident sunshine is direct radiation and the yearly sunshine hour is usually over 3000 . Equatorial belt which is lying between $15^{\circ} \mathrm{S}$ to $15^{\circ} \mathrm{N}$ receives about 2300 hours of sunshine per year with very little seasonal variation. This geographical zone experiences high humidity and frequent clouds in this belt generally result in a high proportion of the solar radiation taking the form of scattered radiation. Nigeria is situated between $4^{\circ} \mathrm{N}$ and $13^{\circ} \mathrm{N}$ latitude which is geographically in a favorable zone for harnessing solar energy. The total solar energy incident on a horizontal surface annually in Nigeria is $2300 \mathrm{kwh} / \mathrm{m}^{2}[9,26]$.

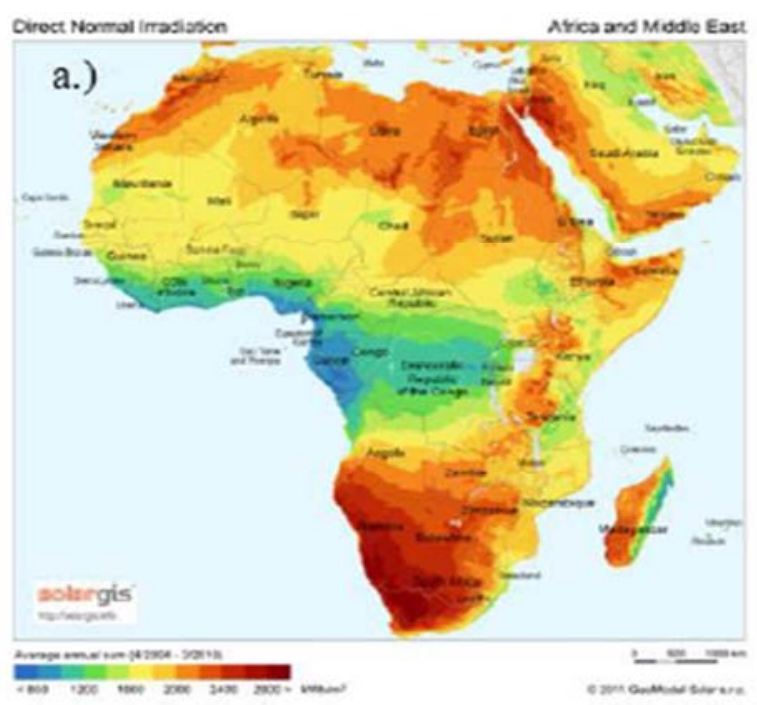

(a)

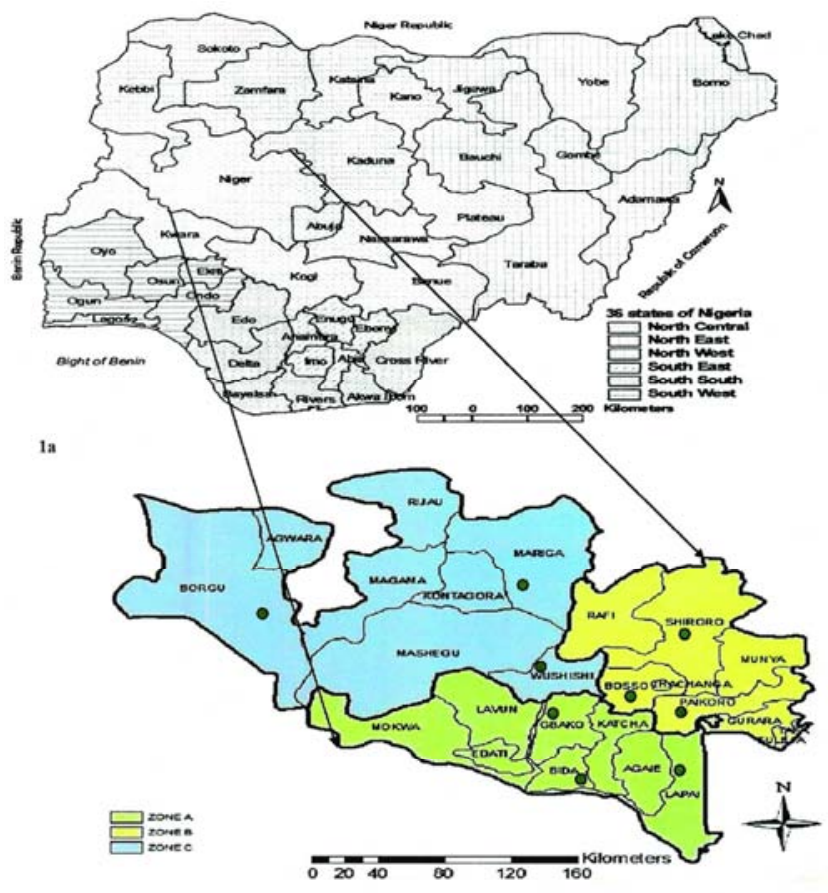

(b)

Figure 2. Location Maps: (a) Africa (b) Niger State.

\subsection{Design Considerations}

Parabolic solar cookers concentrate the Sun's ray from each reflecting mirror to the focal point (focus). Hence, when the Sun's ray hit the concentrator surface side of the device, the curvature which is the shape of the cooker causes all of the rays to be focused at a point. This allows heating up of whatever that is placed there (at focal point). Concentrator is 
the device which collect and directs the radiation to the receiver placed within the parabolic dish. Concentration ratio (C) of the area of energy utility of the device is the ratio of the following points were considered in the design of the parabolic cooker (i) clean inner parabolic surface area to reflect the sun's ray; (ii) the parabolic dish (reflector) was on some platform to incline it in the direction of the sun; (iii) weight consideration of the cooker when it comes to its movement; (iv) cookware (pot) positioning (pot base or hanger); and (v) cost of construction or production.

Table 1. Bill of Quantity.

\begin{tabular}{lll}
\hline Material & Qty & Total Cost (N) \\
\hline 10 m (20 by 20mm) pipe & 1 & 800.00 \\
(8'x4') steel plate of (0.5mm thick) & I sheet & $2,200.00$ \\
2' angle iron & 2 & $3,850.00$ \\
M13 bolts, nuts and washers & 34 & $1,080.00$ \\
$60 \mathrm{~mm}$ Q Wheel pedestal & 4 & 450.00 \\
$5 \mathrm{~mm}$ rod & 3 & 500.00 \\
$2 \mathrm{~mm}$ thick mirror sheet & 1 sheet & $5,000.00$ \\
$5 \mathrm{~mm}$ thick rubber lining & 1 sheet & 500.00 \\
$20 \mathrm{~mm}$ tick pot holder and frame handle & 1 & 900.00 \\
200 mm Q cooking pot & 1 & 200.00 \\
$0.75 \mathrm{~kg}$ Silicon gum & 4 & $2,400.00$ \\
1 bond glue & 1 litre & 800.00 \\
M14 threaded road and nuts & 1 & 600.00 \\
20 mm Q wooden handle & 3 & 300.00 \\
\hline
\end{tabular}

Design Equation

The imaginary sphere area, and the cross-sectional area of the earth with the radius of the sphere, extraterrestrial radiation, extraterrestrial solar constant, continental land area and radius of the earth were the fundamental parameter used in the design.

$$
\begin{gathered}
\mathrm{A}_{\mathrm{E}}=\pi \mathrm{r}_{\mathrm{e}}^{2}=3.142\left(6.4 \times 10^{6}\right)^{2}=1.287 \times 10^{14} \mathrm{~m}^{2} \\
\mathrm{~S}_{\mathrm{S}}=4 \pi \mathrm{r}_{\mathrm{S}}^{2}=4 \times 3.142\left(1.5 \times 10^{11}\right)^{2}=2.828 \times 10^{23} \mathrm{~m}^{2} \\
\text { \%Sun output }=\left\{\left[\mathrm{A}_{\mathrm{E}} / \mathrm{S}_{\mathrm{S}}\right] \times 100\right\} \\
\mathrm{R}_{\mathrm{c}}=\mathrm{I}_{\mathrm{SC}} \mathrm{A}
\end{gathered}
$$

where, $S_{S}$ is the area of the imaginary sphere, $A_{E}$ is referred to as the cross-sectional area of the earth, $\mathrm{r}_{\mathrm{s}}$ is known as the radius of the sphere, $R_{c}$ is the extraterrestrial radiation, $I_{S C}$ is the extraterrestrial solar constant, $\mathrm{A}$ is the continental land area and $r_{e}$ is the radius of the earth. From Eq. (3), it is observed that the sun output could be as much as $0.0000000455 \%$. This output of the sun's energy on the earth $(0.0000000455 \%)$ can definitely support life on earth. Since the world's average annual energy consumption is $9.262 \times 10^{23}$ $\mathrm{kWh}$ [9], this implies that, from Eq. (4), that the extraterrestrial radiation is $1.262 \cdot 10^{15} \mathrm{w} / \mathrm{m}^{2}$. Considering the annual average sun shine for 9 hours/day this energy will amount to $4.157 \cdot 10^{18} \mathrm{wh} /$ year. With the estimation of clearness index of $50 \%$ and since $47 \%$ of the extraterrestrial radiation reaches the earth surface this means that the terrestrial radiation in Nigeria's land area is $2.079 \cdot 10^{18}$ wh/year.

\subsection{Pot Holder}

The pot holder as shown in Figure 1 was constructed using a $5 \mathrm{~mm}$ rod mild steel to enable the pot (s) to maintain balance. With this holder, the cookware is established and the cooking pots were placed on the cookware which also form the focal point where uniform heat distribution is achieved [31-38]. Regardless of the dish tilt inclination angle, the pot is effortless placed on the pot-holder even as the device is been used to tracked the solar movement and elevation which contributes to asymmetry of the cooker. Though the reflector faces the sun, the cookware remains horizontal within the dish. The cross-section of the asymmetric reflector tilt angle between their axes may be as low as zero [28-30], Figure 3, Figures 4 and 5, demonstrate the characteristics of the sun's beam of light been reflected off a flat mirror. The incident ray hits the mirror at the incidence point, a line perpendicular to the mirror i.e. the normal, acts as a line of symmetry for the incident ray and the reflected ray. The angle made between the reflected ray and the normal is the angle of incidence, although they are always identical. For curvature surfaces, the normal is perpendicular to the tangent at the incidence point shown in Figure 5.

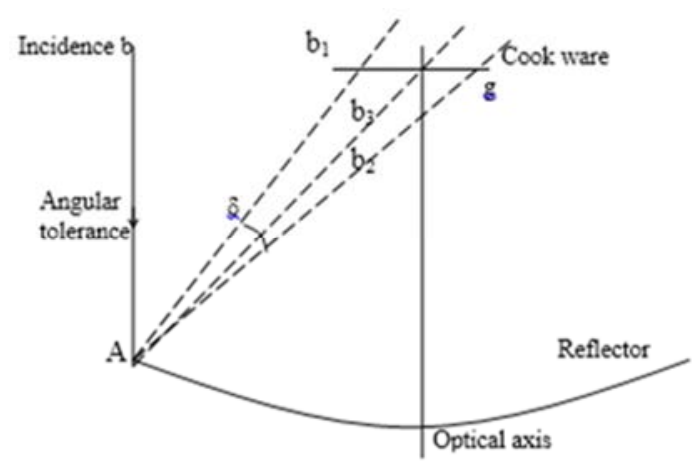

Figure 3. Asymmetric reflector Cross-section.

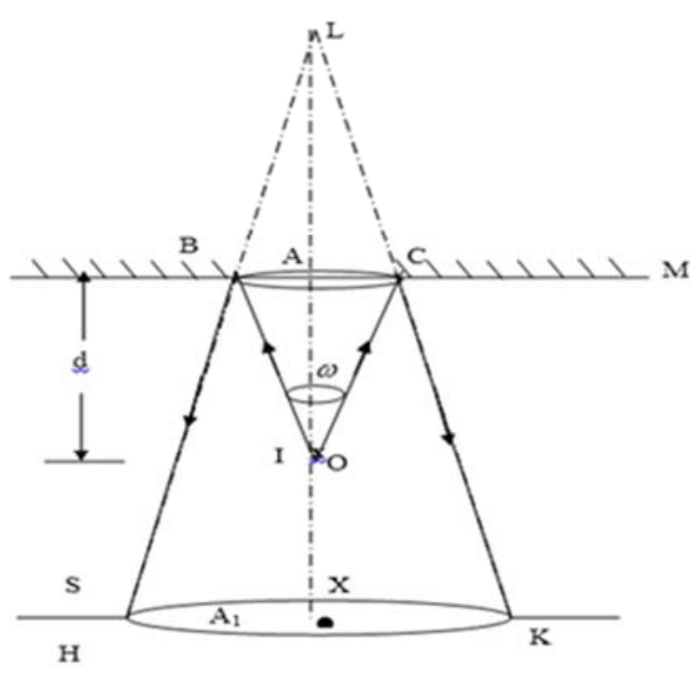

Figure 4. Plane mirror illumination.

\subsection{The Geometry of a Parabolic Dish Multi-Solar Cooker}

A parabolic curvature is the locus of points that moves 
within an equal distance with a fixed line and a fixed point. The perpendicular fixed line serves as the directory while the fixed point is known as the focal point $\mathrm{F}$ as shown in Figure 6. The perpendicular line is mathematically known as the axis of the parabola; the parabola intersects its axis at a point $\mathrm{V}$ which is called the vertex, the vertex point dissects the parabola exactly at the midpoint between the focus and the directory. Designing a parabolic curvature, it is more useful to define the design with the origin at $\mathrm{F}$ and in terms of the angle $(\theta)$ in polar coordinates with the origin at $F$. The angle $\theta$ on the line VF and the parabolic radius $p$, specified the distance of the focus $\mathrm{F}$ to the curve. Repositioning the origin to the focus F, we have Eq. 5 [14, 39, 40].

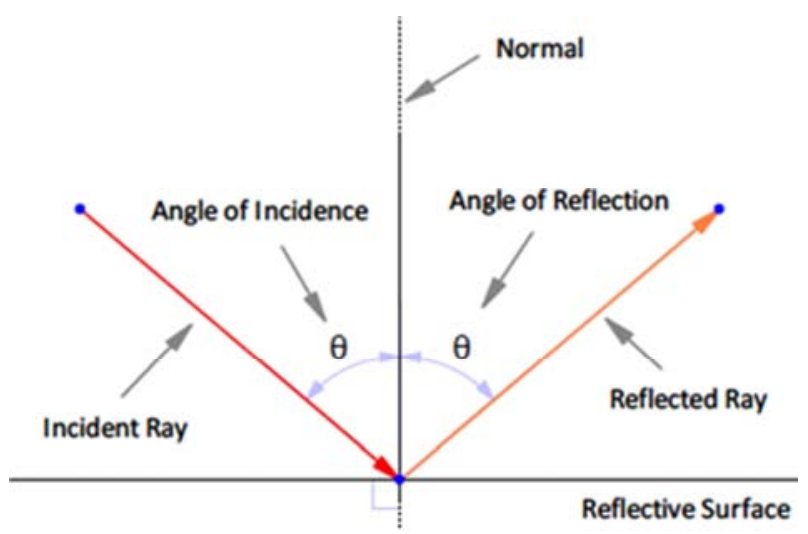

Figure 5. Light reflects off a flat mirror.

$$
P=\frac{2 f}{1+\cos \theta}
$$

The rim angle $\left(\theta_{\text {rim, }}\right)$ can be determined in terms of the parabola dimensions using Eq. 6:

$$
\operatorname{Tan} \theta_{\text {rim }}=1 /(\mathrm{d} / 8 \mathrm{~h})-(2 \mathrm{~h} / \mathrm{d})
$$

From the physics of parabola, for any line parallel to the axis of the aperture reflecting surface, the angle $p$ between it and the surface normal is equal to the angle between the normal and a line to the focal point as shown in Eq. 7.

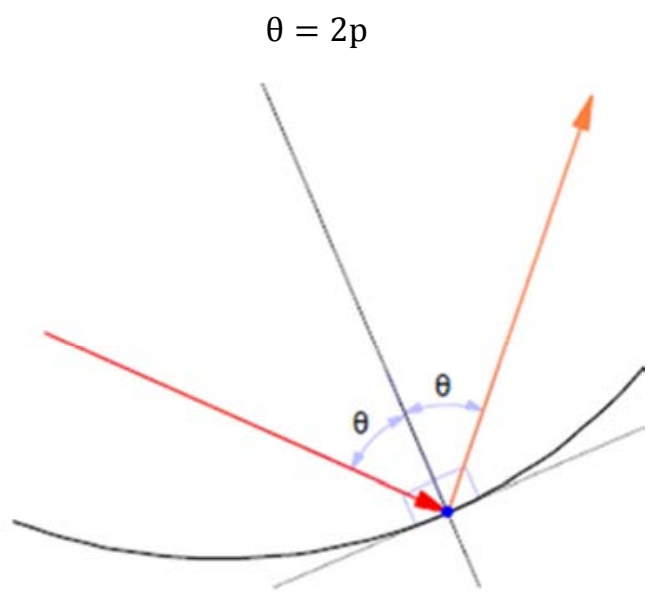

Figure 6. The parabola intersection.

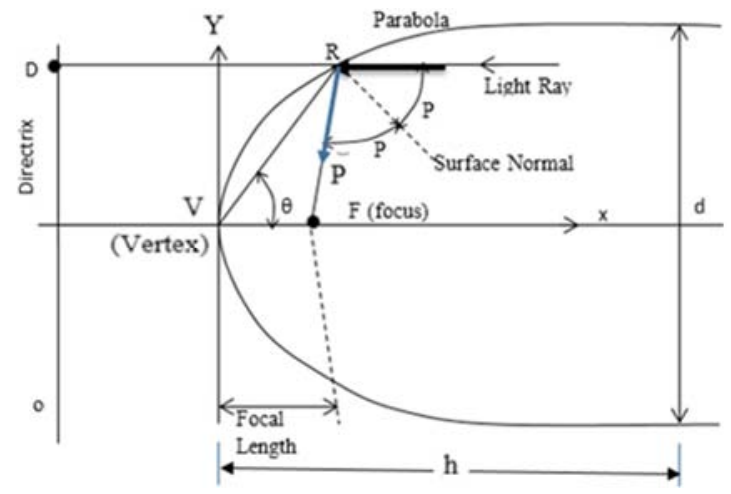

Figure 7. Parabolic curvature.

When considering integrating a differential segment of the curve in Figure 7 and applying the limits $\mathrm{x}=\mathrm{h}$ and $\mathrm{y}=\mathrm{d} / 2$, Equation 8 was obtained.

$$
s=\left[\frac{d}{2} \sqrt{\left(\frac{4 h}{d}\right)^{2}+1}\right]+2 f \ln \left[\frac{4 h}{d} \sqrt{\left(\frac{4 h}{d}\right)^{2}+1}\right]
$$

Where $\mathrm{d}$ is defined as the distance across the aperture in Figure 7 while $\mathrm{h}$ is taken to be the distance from the vertex to the aperture. The cross-sectional area of the aperture space of the parabola and a line across its aperture with the normal to the axis is given by

$$
A_{x}=\frac{2}{3} d \cdot h
$$

Care should be taken not to assume that the reflecting surface area of a parabolic trough or dish or their aperture areas are the same, [22]. Figure 8 shows the parabolic curvature.

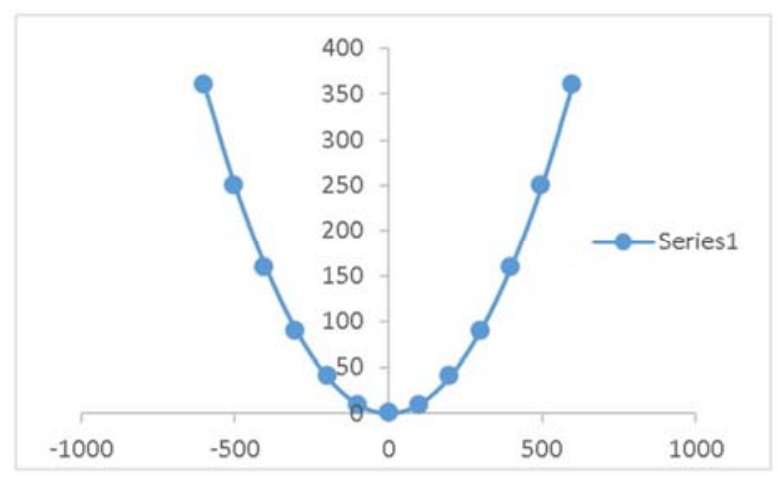

Figure 8. Parabolic curvature.

\subsection{Parabolic Size Calculations}

Using the design specification, the diameter, $\mathrm{d}=1200 \mathrm{~mm}$, for good convergence, while the depth is taken to be $300 \mathrm{~mm}$. At $y=300 \mathrm{~mm}$ (depth of parabolic dish) and $\mathrm{x}=600 \mathrm{~mm}$ radius of parabolic dish). The calculations of the focal length (f), rim angle $(\theta)$ and the parabolic radius $(\mathrm{P})$ were done using Eqs. 10, 11 (from depth, $\mathrm{H}$ ), and 12, respectively

$$
y=x^{2} / 4 f
$$

$$
\operatorname{Tan} \theta=\frac{1}{(\mathrm{~d} / 8 \mathrm{H}) \div(2 \mathrm{H} / \mathrm{d})}
$$




$$
P=2 f / 1+\cos \theta(m)
$$

\subsection{Calculation of the Theoretical Quantity of Heat Needed for Cooking}

The quantity of heat needed for cooking is obtained from all the heat quantities utilized in the cooking of food in relation to the design insolation as shown in Eqs. 13-16

Useful heat $\left(\mathrm{Q}_{1}\right)$

Heat required to boil $1 \mathrm{~kg}$ of $\mathrm{H}_{2} \mathrm{O}, \mathrm{Q}_{1}$

$$
\mathrm{Q}_{1}=\mathrm{M}_{\mathrm{c}} \Delta \mathrm{T}
$$

$$
1 \times 4200 \times(100-30)=294,000 \mathrm{~J}=294 \mathrm{~kJ}
$$

Latent heat required to maintain the boiling point of water

$$
\begin{gathered}
\mathrm{Q}_{2} \mathrm{Q}_{2}=\mathrm{ML} \\
1 \times 0.5 \times 2.26 \times 10^{6}=113,000 \mathrm{~J}=113 \mathrm{~kJ} .
\end{gathered}
$$

Heat losses

Heat dissipated to free convection by pot $\mathrm{Q}_{3}$

$$
\mathrm{Q}_{3}=\ell^{2} \mathrm{KN}_{\mathrm{u}} \Delta \mathrm{T} / \mathrm{h}_{\mathrm{p}}
$$

The turbulence heat which occurs at the bottom of the pot, $\mathrm{Nu}=0.14 \mathrm{G}^{0.33}$

This shows that $\mathrm{G}$ is obtained from a factor given as $\mathrm{G} / \mathrm{d}^{3} \Delta \mathrm{T}=5.8 \times 10^{7}$, From the relationship the Rayleigh number is given by:

$$
\begin{gathered}
\mathrm{G}=\mathrm{d}^{3} \Delta \mathrm{T} \times 5.8 \times 10^{7} \\
=(0.13)^{3} \times 5.8 \times 10^{7} \times(100-300)=8919820
\end{gathered}
$$

From Eq. 15,

$$
\Rightarrow \mathrm{N}_{\mathrm{u}}=0.14(8919820)^{0.33}=27.526
$$

Heat loss by the pot through convection $\mathrm{Q}_{3}$

$$
\begin{gathered}
\mathrm{Q}_{3}=\rho^{2} \mathrm{KN}_{\mathrm{u}} \Delta \mathrm{T} / \mathrm{h}_{\mathrm{p}} \\
=(0.075)^{2} \times 0.027 \times 27.526 \times(100-30) / 0.08 \\
=2.9264 \mathrm{w}=0.00293 \mathrm{Kw}
\end{gathered}
$$

The amount of power over the period of an hour

$P_{\text {input }}=Q_{1}+Q_{2}=294000+113000 / 3600=395.55 \mathrm{w}$

Amount of power $(\mathrm{P})$ at the cook ware

$\mathrm{P}=$ useful power + losses

$$
\mathrm{P}=\mathrm{Q}_{1}+\mathrm{Q}_{2}+\mathrm{Q}_{3}=395.55+2.9264=398.4764 \mathrm{w}
$$

But useful energy=energy supplied - energy loss Useful power=Power Supplied - Power Loss

$$
\mathrm{P}_{\mathrm{Up}}=\mathrm{P}_{\mathrm{S}}-\mathrm{P}_{\mathrm{L}}
$$

The energy expected to be supplied will depend on the area of the collector and the effective solar beam (Ie)

$$
\mathrm{Ie}=\mathrm{P} \times \mathrm{T}
$$

where Ie is the effective solar beam, e is the reflectance of back - silvered mirror, I is the solar insolation and $\mathrm{P}$ is the solar reflectance of back silvered plain mirror.

The energy balance for the working of the solar cooker will be:

$$
\text { Ale }=Q_{1}+Q_{2}+Q_{3}=P_{U P}+P_{L}
$$

But

$$
\begin{gathered}
\mathrm{A}=\mathrm{P}_{\mathrm{UP}}+\mathrm{P}_{\mathrm{L}} / \mathrm{Ie} \\
=395.55+2.9264 / 750 * 0.89=0.473 \mathrm{~m}^{2}
\end{gathered}
$$

By considering a design factor of 1.5

$$
\begin{gathered}
\mathrm{A}=\mathrm{P}_{\mathrm{UP}}+\mathrm{P}_{\mathrm{L}} / \mathrm{Ie} * 1.5=0.473 * 1.5=0.709 \mathrm{~m}^{2} \\
\text { Given that } \mathrm{A}=\pi \mathrm{r}^{2}=0.709 \mathrm{~m}^{2} \\
\mathrm{r}=\sqrt{0.709} / \pi=0.268 \mathrm{~m}^{2}
\end{gathered}
$$

\subsection{Calculation of the Concentration Ratio of the Solar Cooker}

The aperture area of the solar device $A_{a}$ is the actual area of the concentrator facing the beam. The concentration ratio of this area is the ratio of the aperture area to the area of the absorber $\left(\mathrm{A}_{\mathrm{b}}\right)$ as shown in Eq. 17

$$
\mathrm{q}_{\mathrm{cm}}=\mathrm{A}_{\mathrm{a}} / \mathrm{A}_{\mathrm{b}}
$$

The individual plane or curved segments are each designed to reflect radiation to the absorber.

Substitution of $\mathrm{R}=1.2$ and $\mathrm{r}=0.2$ in the relation $\mathrm{q}_{\mathrm{cr}}=$ $\pi r\left(R^{2}-r^{2}\right) / \pi r^{2}+2 \pi r h=\left(R^{2}-r^{2}\right) / r^{2}+2 r h \quad, \quad$ we obtained $\mathrm{q}_{\mathrm{cr}}$ to be 25.75 .

\subsection{Thermal Analyses of the Cooker}

The parabolic cooker is theoretically design to reach a max temperature of $240^{\circ} \mathrm{C}$. Therefore, the assumptions made during the construction and test of the equipment were that the absorber theoretical temperature is uniform, the air within the environment surrounding the absorber and mirror elements is at ambient temperature and that during sunny days the humidity is negligible. Thus, form the assumption, observation and conditions, the energy balance equations for a parabolic solar cooker (constructed) are shown in Eqs. 1823.

$$
\mathrm{Q}_{\mathrm{u}}=\mathrm{Q}_{\mathrm{ab}}-\mathrm{Q}_{\mathrm{c}}-\mathrm{Q}_{\mathrm{e}}
$$

Where $Q_{u}$ is the energy utilized/sec for heating the absorber and the liquid, $\mathrm{Q}_{\mathrm{ab}}$ is the total energy reflected directly into the absorber surface, $\mathrm{Q}_{\mathrm{c}}$ is the convection losses/sec and $\mathrm{Q}_{\mathrm{R}}$ is the radiation losses/sec. Therefore, the total heat energies

$$
\begin{gathered}
Q_{a b}=H_{n} A_{3} \cdot \text { e. } \alpha_{a}+H_{n} \cdot A_{2} \cdot \alpha_{a} \\
Q_{c}=\left(h_{1 a} A_{1}+h_{2 a} \cdot A_{g}\right)\left(T_{s}-T_{a}\right) \\
Q_{R}=\frac{\varepsilon}{I-\varepsilon}\left\{A_{1}\left(\sigma T_{s}^{4}-J_{1}\right)+A_{2}\left(T_{s}^{4}+J_{2}\right)\right\}
\end{gathered}
$$


where $\mathrm{J}_{1}$ and $\mathrm{J}_{2}$ are given by Sparrow and Bahadori as

$$
\begin{aligned}
\mathrm{J}_{1} & =(\mathrm{I}-\varepsilon)\left\{\varepsilon_{\mathrm{g}} \mathrm{F}_{1-2}+\varepsilon_{\mathrm{G}} \mathrm{F}_{1-3}\right\} \sigma \mathrm{T}_{\mathrm{s}}^{4} \\
\mathrm{~J}_{2} & =(\mathrm{I}-\varepsilon)\left\{\varepsilon_{\mathrm{g}} \mathrm{F}_{2-\mathrm{g}}+\varepsilon_{\mathrm{a}} \mathrm{F}_{2-\mathrm{a}}\right\} \sigma \mathrm{T}_{\mathrm{a}}^{4}
\end{aligned}
$$

and $\mathrm{H}_{\mathrm{n}}=$ solar insulation $-750 \mathrm{kw} / \mathrm{m}^{2}$

The energy $\mathrm{Q}_{\mathrm{u}}$ is utilized in heating the absorber and the liquid. An increase in the temperature $\nabla \mathrm{T}$ in time $\nabla \mathrm{t}$ is given as Eq. 24:

$$
\mathrm{Q}_{\mathrm{u}} \nabla \mathrm{t}=\mathrm{M}_{\mathrm{a}} \mathrm{C}_{\mathrm{pa}} \nabla \mathrm{T}+\mathrm{M}_{\mathrm{w}} \mathrm{C}_{\mathrm{pw}} \nabla \mathrm{T}
$$

The heat transfer co -efficient $h_{1 a}$ and $h_{2 a}$ depend on the wind velocity $V_{0}$

$$
\begin{aligned}
\mathrm{H}_{1 \mathrm{a}} & =0.174 \frac{\mathrm{K}_{\mathrm{a}\left(\mathrm{V}_{0} \mathrm{~d} \operatorname{Cos} \alpha\right)^{0.618}}}{\mathrm{dv}} \\
\mathrm{h}_{2 \mathrm{a}} & =0.664 \frac{\mathrm{K}_{\mathrm{a}} \operatorname{Rea}^{1 / 2} \operatorname{Pra}^{1 / 3}}{0.88 \mathrm{~d}}
\end{aligned}
$$

When the wind velocity is reduced to zero by shielding the pot, the heat dissipation between the absorber to the air will be by free convection and the heat transfer co - efficient in that case will be:

$$
\begin{gathered}
H_{1 a b}=0.53 \frac{K_{a(\text { Gra } . \operatorname{Pra} \operatorname{Cos} \alpha)^{1} 4}}{d} \\
H_{2 a i r}=0.53 \frac{K_{a(\text { Gra.Pra })^{1} 4}}{0.88 d}
\end{gathered}
$$

\subsection{Calculations of the Theoretical Quantity of Heat Needed for Cooking When Using Aluminum Pot}

$$
\text { The Grashof number } \mathrm{Gr}_{\mathrm{a}}=\frac{\mathrm{g} \beta \nabla \mathrm{TL}}{\mathrm{v}^{2}}
$$

The $\mathrm{Gr}_{\mathrm{a}}$ is thus obtained as 230.88

The average heat dissipation coefficient between the absorber surface $\left(\mathrm{h}_{1 \mathrm{ab}}\right)$ and the heated surrounding air $\left(\mathrm{h}_{\text {2air }}\right)$ is 1.151 and $1.536 \mathrm{w} / \mathrm{m}^{2} \mathrm{k}$, receptively.

$$
\begin{aligned}
& \mathrm{J}_{1}=(\mathrm{I}-\varepsilon)\left\{\varepsilon_{\mathrm{g}} \mathrm{F}_{1-2}+\varepsilon_{\mathrm{a}} \mathrm{F}_{1-3}\right\} \sigma \mathrm{T}_{\mathrm{a}}^{4}=25.85 \mathrm{w} / \mathrm{m}^{2} \\
& \mathrm{~J}_{2}=(\mathrm{I}-\varepsilon)\left\{\varepsilon_{\mathrm{g}} \mathrm{F}_{2-\mathrm{g}}+\varepsilon_{\mathrm{a}} \mathrm{F}_{2-\mathrm{a}}\right\} \sigma \mathrm{T}_{\mathrm{a}}^{4}=26.22 \mathrm{w} / \mathrm{m}^{2}
\end{aligned}
$$

The diameter of pot $=0.2 \mathrm{~m}$ and height of pot $=0.12 \mathrm{~m}$, then Curve surface area of pot $\left(\mathrm{A}_{1}\right)=0.0754 \mathrm{~m}^{2}$ and the top surface area of pot $\left(\mathrm{A}_{2}\right)=0.034 \mathrm{~m}^{2}$

Heat loss through radiation $\mathrm{Q}_{\mathrm{R}}$

$$
Q_{R}=\frac{\varepsilon}{I-\varepsilon}\left\{A_{1}\left(\sigma T_{f a}^{4}-J_{1}\right)+A_{2}\left(T_{f a}^{4}+J_{2}\right)\right\}=40.33 \mathrm{~W}
$$

Heat loss through convection

$$
Q_{c}=\left(h_{1 a} A_{1}+h_{2 a} \cdot A_{2}\right)\left(T_{f a}-T_{a}\right)=25.63 \mathrm{~W}(26)
$$

The total energy received and reflected on the absorber surface in a second is:

$$
Q_{a b}=H_{n} A_{3} \cdot e \cdot \alpha_{a}+H_{n} \cdot A_{2} \cdot \alpha_{a}
$$

$$
\therefore A_{3}=\frac{Q_{a b}-23.079}{698.25}=0.21 \mathrm{~m}^{2}
$$

A factor of safety of 1.5 is assumed in order to take care of their losses not considered, the total collector area will now be $0.314 \mathrm{~m}^{2}$.

Efficiency determination of multi-solar device.

Multi-solar device thermal efficiency was calculated using Eq. 27.

$$
\text { Thermal Energy }=\frac{\text { Focus Energy }}{\text { Energy recceived at the dish }}
$$

Taking the focused energy=energy obtain at the potholder with the energy obtained is equal to the total energy radiated through the sun that hits the dish and thus was computed; Eq. 28.

$$
\mathrm{E}=\mathrm{A} \delta \mathrm{T}^{4}
$$

where $E$ is he total amount of energy radiated $\left(\mathrm{W} / \mathrm{m}^{2}\right), \delta$ is Stefan constant with the value of $5.7 \times 10^{-8} \mathrm{~W} / \mathrm{m}^{2} \mathrm{~K}^{4}$, while $\mathrm{T}$ is the temperature $(\mathrm{K})$ and $\mathrm{A}$, area of the potholder.

The cooker efficiency was computed to be $44 \%$. Actually, the atmosphere created a negative environment for serious no effectiveness of the reflecting surfaces and incomplete reflection of this ray to the focus due to inaccurate curvature. Nevertheless, since the cooker was designed for cooking, the only thing that affects the efficiency of this cooker is when the intensity of the sun is low and there are clouds in the sky [11]

\section{Result and Discussion}

The focal point temperature varied with time as the sunshine intensity increases but however, a peak value was realized during the experiment and there after the intensity begin to decrease. Incremental changes of the sun temperature with time are conditioned by the sun movement, sun tracking, and the inclination angle of the parabolic dish to the atmospheric condition. Experimental procedures were followed during the test and this includes testing for the temperature highest point at the focus at various intervals using a paper tissue; taking the readings of the cooking period of the cooker for different type of cooking items. The solar device temperature at the cookware focus where the pot is placed was determined at intervals; the experimental activities were done during the period of cooking. The change in temperatures during the experiment were between $9 \mathrm{am}$ in the morning to $4: 30 \mathrm{pm}$ as shown Figure 9: The average temperature obtained was $105^{\circ} \mathrm{C}$. In this experiment different type of food items were cooked simultaneously for different people at a time using a multi-cookware principle. The cooking was absolutely alright for eating. The quantity of heat absorbed can be obtained using definite calculation equations. The temperature variation was as a result of the weather changes. The use of wider cooking pot-holder Figure 1 enables us to achieve our desire of concurrent boiling of different food items. During this test, three food items were taken into consideration: yam, rice and water. The effective 
period of temperature changes is from 11 am for both Yam $(1.5 \mathrm{~kg})$ and Rice $(1 \mathrm{~kg})$ with ingredients $(0.2 \mathrm{~kg})$ while that of the water $(1 \mathrm{~kg})$ is 1:00 pm. The heat addition between 9 am to 11 am was not remarkable due to the cloudy day. Table 4 gives detail information on the concurrent cooking procedure; this is a step further for the utilization of solar cookers for an average family. After every 15 minutes, the cooker was mechanically tracked using mechanical tracking device for perfect focusing continuously to obtain the solar intensity as the sun transverse across the sky. A digital temperature recording device and bulb thermometers were deployed to measure the temperatures of the cooking elements within the interval period of 10 and 30 minutes, respectively. The tracking of the cooker is highly necessary during the experiment for cooking to capture the reflected rays for the luminous flux for utility. Frying of half a dozen of eggs weighing $0.5 \mathrm{~kg}$ was done with the aids of a solar meter and a thermometer (Table 2). Pouring $1 \mathrm{~kg}$ of water into the cooking pot and adding rice $(1 \mathrm{~kg})$ and ingredients $(0.2$ $\mathrm{kg}$ ) the temperature of water was raised to between 75 and $80^{\circ} \mathrm{C}$. Different observations were carried out on rice $(1 \mathrm{~kg})$ and ingredients $(0.2 \mathrm{~kg})$. A measured quantity of rice and ingredients were considered and two experimental observations were noted for each day at different time interval. The experimental results recorded are tabulated in Tables 3 also in 4, respectively.

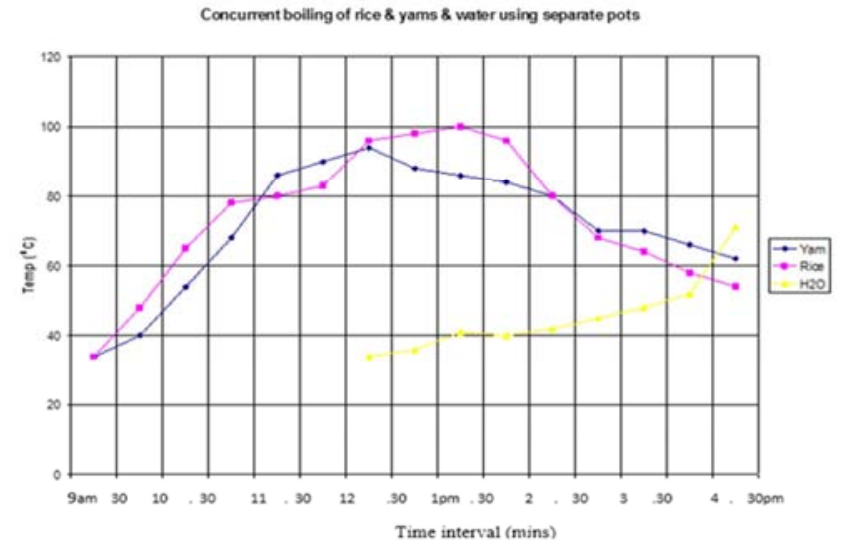

Figure 9. Temperature readings for concurrent cooking from 9am to 4:30pm.

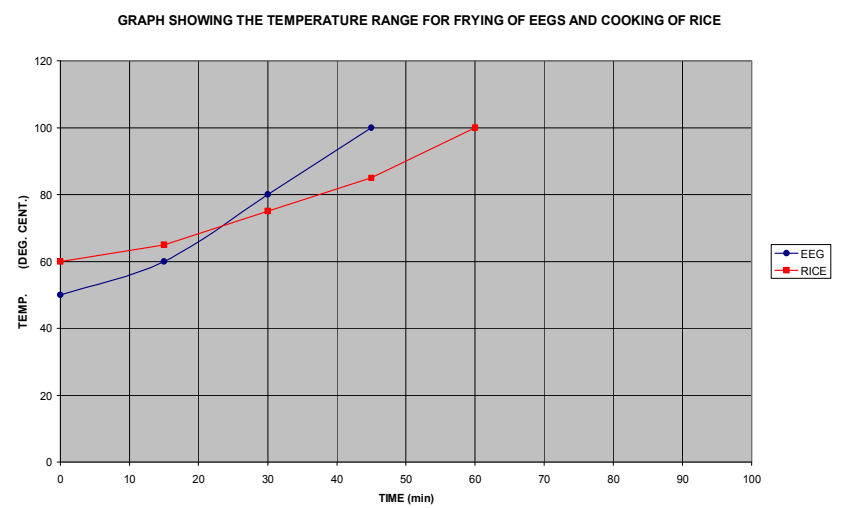

Figure 10. Temperature readings for eggs and rice from 12 noon to $3: 30 \mathrm{pm}$.

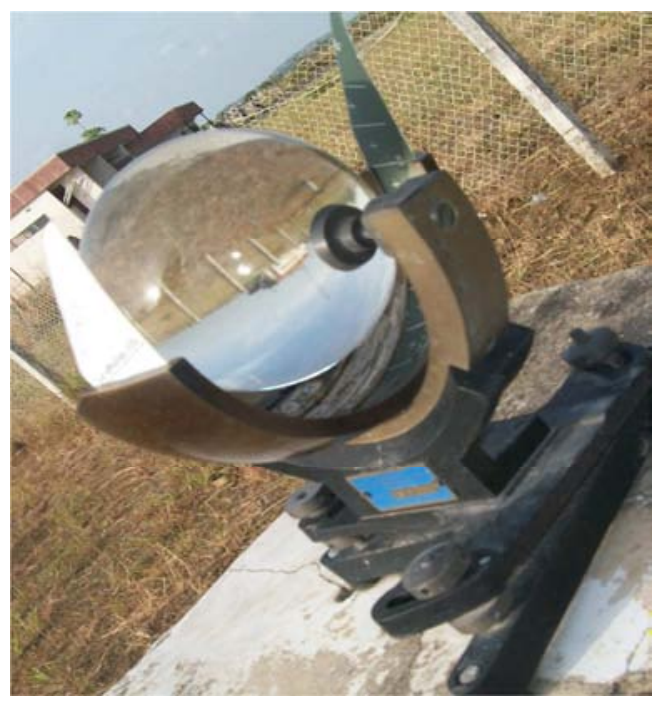

Figure 11. Sun-shine recorder instrument.

During the experiment, glass bulb thermometer and a digital thermometer were used to record the temperature, Figure 1 . The daily sunshine radiation during the observation was recorded through the sunshine record Figure 11. This recorder is used to verify the intensity of the sun. This instrument has a component called, sunshine card under the glass ball, graduated on hourly recording Figure 11. As the temperature of the sun increases this card get burnt and at this point the reading is noted from the card [11]. The temperature variation of water, yam, eggs, rice and ingredients during the experiment and time are plotted and shown in Figure 9 to Figure 10. Experimental observations from Figures 8 to 9 show that the cooking pot temperature increased with time. The same observation can be said during the concurrent cooking as the temperature keep increasing of each food item with time. This phenomenal of increment changes in temperature was because of the variation of energy intensity as the sun is been tracked. The experiment was favored with a sunny day unabated by dark cloud therefore the radiation was high and also the temperature was high. Again from the data of cooking, Figure 9, it was observed that the highest temperature for $1 \mathrm{~kg}$ rice and ingredients $0.2 \mathrm{~kg}$, is $100^{\circ} \mathrm{C}$. In this location, Nigeria is lies between $4^{\circ} \mathrm{N}$ and $13^{\circ} \mathrm{N}$ latitude and is geographically favored for harnessing solar energy, therefore the maximum solar radiation cooking energy is observed between 9:00 am to 2:30 pm, as from this time on-forward the solar radiation begin to decrease to sun set this is because Niger State lies within moderate levels of solar radiation. The data in Table 4 indicate the temperature dependence of water in the receiver as the solar radiation increases during day time. From the data it can be understood that the temperature of the water changes during the day time between $12: 30$ to $2: 30 \mathrm{pm}$ due to the heat flux of solar radiation which enable the yam to be cooked [11]. Due to the decrease in the sun's intensity the solar radiation also keep falling thereby making the water temperature to begin to fall as from $2: 30 \mathrm{pm}$ with time. Finally, the cooker can perform better to about $150^{\circ} \mathrm{C}$ if constant positioning of the pot is at the focal points. 
Table 2. Monitoring during when used to fry eggs (experimental time: 11:45 am, ambient temperature: $35^{\circ} \mathrm{C}$ ).

\begin{tabular}{lll}
\hline MM (kg) & TI & TR $\left({ }^{\circ} \mathrm{C}\right)$ \\
\hline 0.5 & $1200 \mathrm{hrs}$ & 50 \\
0.5 & $1215 \mathrm{hrs}$ & 60 \\
0.5 & $1230 \mathrm{hrs}$ & 65 \\
0.5 & $1300 \mathrm{hrs}$ & 105 \\
\hline
\end{tabular}

*MM-mass of materials, TI: time interval, TR-thermometric readings
Table 3. Monitoring during when used to cook rice (experimental time: 1:40 pm, ambient temperature: $36^{\circ} \mathrm{C}$ ).

\begin{tabular}{lll}
\hline MM (kg) & TI & TR $\left({ }^{\circ} \mathrm{C}\right)$ \\
\hline Mass of $\mathrm{H}_{2} \mathrm{O}=1$ & $1400 \mathrm{hrs}$ & 75 \\
Mass of Rice $=1$ & $1430 \mathrm{hrs}$ & 82 \\
Mass of pot $=0.2$ & $1500 \mathrm{hrs}$ & 90 \\
Mass of ingredients $=0.2$ & $1530 \mathrm{hrs}$ & 105 \\
\hline
\end{tabular}

*MM-mass of materials, TI: time interval, TR-thermometric readings

Table 4. Monitoring during when used to concurrently cook yam and rice and to boil water (experimental time: 9 am (for yam and rice), 12 noon (for water) ambient temperature: $34^{\circ} \mathrm{C}$ ).

\begin{tabular}{|c|c|c|c|c|c|c|}
\hline \multirow{2}{*}{ MM (kg) } & \multicolumn{3}{|l|}{ TI } & \multicolumn{3}{|c|}{ TR $\left({ }^{\circ} \mathrm{C}\right)$} \\
\hline & Yam & Rice & $\mathrm{H}_{2} \mathrm{O}$ & Yam & Rice & Water \\
\hline Mass of $\mathrm{H}_{2} \mathrm{O}=1$ & 1100 & 1100 & 1300 & 86 & 80 & 41 \\
\hline Mass of Yam=1.5 & 1130 & 1130 & 1330 & 90 & 83 & 40 \\
\hline \multirow[t]{2}{*}{ Mass of pot $=0.1$} & 1230 & 1230 & 1430 & 88 & 98 & 45 \\
\hline & 1300 & 1300 & 1500 & 86 & 100 & 48 \\
\hline \multirow[t]{2}{*}{ Mass of ingrédients $=0.2$} & 1330 & 1330 & 1530 & 84 & 96 & 52 \\
\hline & 1400 & 1400 & 1600 & 80 & 80 & 71 \\
\hline
\end{tabular}

*MM-mass of materials, TI: time interval, TR-thermometric readings.

\section{Conclusion}

The realization of a steady temperature of $140^{\circ} \mathrm{C}$ no load test means that the cooker achieved its specification temperature for cooking different food items which cooks at $100^{\circ} \mathrm{C}$. Since the multi-cooker cooked the specified food within an appreciable period, it means that the cooker meets its designed aims and objectives. The acceptability and marketability of parabolic solar multi-cooker is a promising one due to its ability to conserve fossil fuels energy, money, and reduced environmental pollution etc. The multi-cooker can be produced using local materials and does not involve complex constructional techniques; an initial capital cost of purchase is sacrosanct and does not involve recurrent cost of running and maintenance of the device unlike its conventional counterparts. The energy utilisation is so decentralized that any user can use it without having to transport it to the site of use. It can therefore be concluded, that the (PDSMC) achieve its objective by using it to cook different food items simultaneously, it's a good substitute to the conventional cookers. The multi-purpose cooking device was tracking the sun angle when the focal height is onefourth of the aperture length regardless of the target size. When the multi-purpose cooking device is positioned at this angle, the device will concentrate all the reflected rays of light to the target despite the angle of the diameter of a given target. The wider the target base (potholder), the more angle tolerant the device will live to its expectation. However, a fulcrum shaped base targets (Pot) can effectively operates within the concentration ratio of the device, which is a huge advantage. Although there is always a trade-off in the design and operations of this types of devices between the angle of tolerance and that of the solar concentration which depends primarily on the target size. Sacrificing one of the design parameter to optimize the other will also depend on the target base and the type of the potholder designed to maximize the heat flux for the purpose of achieving the set goal. Though it is impossible to maximize the both design parameters but it's equally the best to watch out for the optimal thermal efficiency of the device for optimal utility. Finally, from the concluding results obtained when aluminium pot and stainless pots were used, the multi-cooker performed satisfactorily and did not deviate much from the initial assumption made during the designing stage. The multicooker uses an energy that has been generally accepted as the most promising, renewable and non-polluting type of energy.

\section{References}

[1] Adeleke, A. A., Odusote, J. K., Ikubanni, P. P., Lasode, O. A., Malathi, M. \& Paswan, D. (2020). The ignitability, fuel ratio and ash fusion temperatures of torrefied woody biomass, Heliyon, 6 (3), e03582, 1-7.

[2] Adeleke, A. A., Odusote, J. K, Malathi, M., Lasode, O. A. \& Paswan, D. (2019) Influence of torrefaction on lignocellulosic woody biomass of Nigerian origin, Journal of Chemical Technology and Metallurgy, 54 (2), 274-285.

[3] Odusote, J. K., Adeleke, A. A., Lasode, O. A., Malathi, M. \& Paswan, D. Thermal and compositional properties of treated Tectona grandis, Biomass Conversion and Biorefinery, 9 (5), 2019, 511-519.

[4] Mohammed, I. L, Rumah, U. J. \& Abdulrahim A. T. (2013). Performance testing of a truncated pyramid solar thermal cooker, International Journal of Engineering Research and Applications, 3 (4), 1174-1178.

[5] Joyee, E. B. \& Rahman, A. N. M. (2014). Design and construction of a parabolic dish solar cooker. In: International Conference on Mechanical, Industrial and Energy Engineering, Khulna, Bangladesh, 26-27.

[6] Omotoyosi, O. C. (2015). A stand-alone parabolic dish solar cooker for African conditions. M. Eng. Thesis submitted to the Faculty of Engineering, Stellenbosch University, South Africa. 
[7] Adeleke, A. A., Odusote, J. K., Lasode, O. A., Ikubanni, P. P., Malathi, M. \& Paswan, D. (2019). Mild pyrolytic treatment of Gmelina arborea for optimum energetic yields, Cogent Engineering, 6 (1), 1593073, 1-13.

[8] Adeleke, A. A., Odusote, J. K., Lasode, O. A., Ikubanni, P. P, Madhurai, M. \& Paswan, D. (2019). Evaluation of thermal decomposition characteristics and kinetic parameters for melina wood, Biofuels, 1-7, http://doi.10.1080/17597269.2019.1646541.

[9] Joshua, F. (2009). Design, construction and testing of a parabolic solar steam generator. Leonardo Electronic Journal of Practices and Technologies, 14, 115-133.

[10] Ashokraj, S. \& Sekar, M. (2016). Design and analysis of receiver for a parabolic solar dish collector, Department of Mechanical Engineering. Government College of Technology, Coimbatore, Tamil Nadu, India.

[11] Mathew, A. A., Adedayo, J. A., Monsuru, O. A. \& Christopher, K. U. (2020). Modification and construction of solar cooker using parabolic reflector. Engineering and Applied Sciences 5 (1), 28-33.

[12] Ariel, C. (2007). The critical angle and percent efficiency of parabolic solar cookers http://www.blog.thesietch.org/wpcontent/uploads/2007/02/vajra-2006-1.JPG, accessed on $5^{\text {th }}$ April, 2019.

[13] Dasin, D. Y., Asere, A. A. \& Habou, D. (2011). Parabolic solar cooker dish: design and simulation. Nigerian Journal of Solar Energy, 22, 43-51.

[14] Fareed. M. M., Auatf, S. J., Yaseen, H. M. \& Mohamad, A. K. A. (2012). Design and study of portable solar dish concentrator. International Journal of Recent Research and Review, 3.

[15] Masum, A. S. M., Rahmatullah, A. Md., Shakil, A., Foysal, A., Ahmed, M. S. \& Md. Abdur R. (2020). Design, construction and testing of parabolic solar cooker for rural households and refugee camp. Solar Energy, 205, 230-240.

[16] Nosakhale, O. S., Mwaniki, C. \& Akorede, M. F. (2019). Optimal sizing and analysis ofa hybrid energy system for a community microgrid in Nigeria. Journal of Engineering and Applied Sciences, 14 (23), 8769-8778.

[17] Al-Soud, M. S., Abdallah, E., Akayleh, A., Abdallah, S. \& Hrayshat, E. S. (2010). A parabolic solar cooker with automatic two axes sun tracking system. Applied Energy, 87 (2), 463-470.

[18] Bishir, M. \& Raji, H. M. (2016). Quantitative and qualitative analysis of biogas produced from three organic wastes. International Journal of Renewable Energy Research, 6 (1), 299-305.

[19] Adeleke, A. A., Odusote, J. K., Lasode, O. A., Ikubanni, P. P., Paswan, D. \& Malathi, M. (2019). Densification of coal fines and mildly torrefied woody biomass into composite fuel, Heliyon, 5 (7), e02160, https://doi.org/10.16/j.heliyon.2019.e02160.

[20] Adewumi, S. D., Abdulrahim, A. T., Adeleke, A. A., Ikubanni, P. P. \& Agboola, O. O. (2019). Performance evaluation of solar cooker made from locally sourced materials, International Journal of Mechanical and Production Engineering Research and Development, 9 (2), 299-310.
[21] Ogunwale, O. A., Ramonu, J. A. L., Adewumi, S. D., Adeleke, A. A. \& Yahaya, T. (2019). Exergy analysis of a multiple reflector solar box cooker, International Journal of Engineering Research and Technology, 12 (12), 3056-3060.

[22] Oke, M. O., Akinbode, A. O., Sadiq, I. L., Sulaiman, K. A., Olaniyan, S. A. \& Hussein, J. B. (2017). Development and evaluation of an improved electro-mechanical yam pounding machine. LAUTECH Journal of Engineering and Technology, $11(1), 24-32$.

[23] Onokwai, A. O., Okonkwo, U. C., Osueke, C. O., Okafor, C. E., Olayanju, T. M. \& Samuel, O. D. (2019). Design, modelling, energy and exergy analysis of a parabolic cooker. Renewable Energy, 142, 497-510.

[24] Kolawole, A., Ikubanni, P. P., Agboola, O. O. \& Anifowose, O. B. (2018). Development and performance evaluation of an economic solar grain dryer. International Journal of Mechanical Engineering and Technology, 9 (10), 589-604.

[25] Petela, R. (2005). Exergy analysis of the solar cylindricalparabolic cooker. Solar energy, 79 (3), 221-233.

[26] Öztürk, H. H. (2004). Experimental determination of energy and exergy efficiency of the solar parabolic-cooker. Solar energy, 77 (1), 67-71.

[27] Aidan, J. (2014). Performance evaluation of a parabolic solar dish cooker in Yola, Nigeria. IOSR Journal of Applied Physics, 6, 46-50.

[28] Dasin, D. Y., Aliyu, A. S. \& Godi, N. Y. (2015). Verification of the performance of parabolic concentrating solar cooker on some food stuffs cooked in bauchi-North East, Nigeria. In IREC2015 The Sixth International Renewable Energy Congress (pp. 1-5).

[29] Aweda, F. O., Akinpelu, J. A., Falaiye, O. A. \& Adegboye, J. O. (2016). Temperature performance evaluation of parabolic dishes covered with different materials in Iwo, Nigeria. Nigerian Journal of Basic and Applied Sciences, 24 (1), 90-97.

[30] Mohammed, I. L. (2013). Design and Development of a Parabolic Dish Solar Thermal Cooker. International Journal of Engineering Research and Application, 3 (4), 1179-1186.

[31] Olorunshogo B. O., Nnodim, C. T., Oladimeji, S. O., Agboola, B. D., Adeleke, A. A., Ikubanni, P. P., \& Agboola, O. O. (2021). Development and Performance Evaluation of a Manual Briquetting Machine for Biofuel Production, Petroleum and Coal, 63 (2), 509-516.

[32] Ikubanni, P. P., Adeleke, A. A., Agboola, O. O., Adesina, O. S., Nnodim, C. T., Balogun, A. O., Okonkwo, C. J., \& Olawale, A. O. (2021). Characterization of some commercially available Nigerian coals as carbonaceous material for direct reduced iron production, Material Today Proceedings, https://doi.org/10.1016/j.matpr.2020.12.1167.

[33] Nnodim, C. T., Arowolo, M. O., Agboola, B. D., Ogundokun, R. O., \& Abiodun, M. K. (2021). Future Trends in Mechatronics, International Journal of Robotics and Automation, 10 (1), 24-31.

[34] Nnodim C. T., Fath El-Bab A. M. R., Ikua B. W., \& Sila D. N. (2021). Design, Simulation, and Experimental Testing of a Tactile Sensor for Fruit Ripeness Detection, In: Ao SI., Kim HK. Amouzegar M. A. (eds) Transactions on Engineering Technologies. Springer, Singapore. https://doi.org/10.1007/978-981-15-9209-6_5. 
[35] Nnodim C. T., Fath El-Bab A. M. R., Ikua B. W., \& Sila D. N. (2019). Estimation of the Modulus of Elasticity of Mango for Fruit Sorting, International Journal of Mechanical and Mechatronic Engineering. 19 (2), 1-10.

[36] Abdulsalam S. O. et al. (2020) "Performance Evaluation of ANOVA and RFE Algorithms for Classifying Microarray Dataset Using SVM”. In: Themistocleous M., Papadaki M., Kamal M. M. (eds) Information Systems. EMCIS 2020. Lecture Notes in Business Information Processing, vol. 402. Springer, Cham. https://doi.org/10.1007/978-3-030-633967_32.

[37] Nnodim C. T., Fath El-Bab A. M. R., Ikua B. W., \& Sila D. N. (2019). Design and Simulation of a tactile sensor for Fruit Ripeness Detection, Lecture Notes in Engineering and Computer Science: Proceedings of the World Congress on
Engineering and Computer Science, San Francisco, USA, 390-395.

[38] Chukwulozie, O. P., Chinagorom, N. E., Chukwuneke, C. J. \& Nnodim, C. T. (2017). Analysis of Cigarate Production Using Double Exponential Smoothing Model, Academic Journal of Science. 7 (2), 293-308.

[39] Rikoto, I. I. \& Garba, I. (2013). Comparative analysis on solar cooking using box-type solar cooker with finned cooking pot. International Journal of Modern Engineering Research, 3 (3), 1290-1294.

[40] Onokwai, A. O., Okonkwo, U. C., Osueke, C. O., Olayanju, T. M. A., Ezugwu, C. A., Diarah, R. S., Banjo, S. O., Onokpite, E., Olabamiji, T. S., James J. A., and Nnodim C. T., Ibiwoye, M. (2019). "Thermal analysis of solar box cooker in OmuAran Metropolis.” J. Phys. Conf. Ser. 1378, 1-20. 